\title{
Lines from the EANM President and the Congress President
}

\author{
Frans H. M. Corstens \\ Department of Nuclear Medicine, University Medical Center, Geert Grooteplein Zuid 8, 6525 GA Nijmegen, The Netherlands \\ Published online: 13 June 2002 \\ (C) Springer-Verlag 2002
}

Eur J Nucl Med (2002) 29:S25-30

DOI 10.1007/s00259-002-0873-7

Table 1. EANM Congress Presidents and sites

\begin{tabular}{lll}
\hline Year & Congress President & Site \\
\hline 1988 & G.J. Buraggi & Milan, Italy \\
1989 & J. Chambron & Strassbourg, France \\
1990 & J. van der Schoot & Amsterdam, The Netherlands \\
1991 & R. Höfer & Vienna, Austria \\
1992 & J. Pedroso de Lima & Lisbon, Portugal \\
1993 & A. Bischof Delaloye & Lausanne, Switzerland \\
1994 & U. Büll & Düsseldorf, Germany \\
1995 & M. de Roo & Brussels, Belgium \\
1996 & H. Dige-Petersen & Copenhagen, Denmark \\
1997 & J. McKillop & Glasgow, United Kingdom \\
1998 & F. Corstens & Berlin, Germany \\
1999 & I. Carrio & Barcelona, Spain \\
2000 & S. Askienazy & Paris, France \\
2001 & M. Salvatore & Naples, Italy \\
2002 & F. Corstens & Vienna, Austria \\
& &
\end{tabular}

On September 6, 1985 the President and Secretary of the Society of Nuclear Medicine Europe (K.E. Britton and H.A.E. Schmidt, respectively) and the President and Secretary of the European Nuclear Medicine Society (B. Nosslin and P.J. Ell, respectively) signed a contract in London that led to the foundation of a single European nuclear medicine organisation: the European Association of Nuclear Medicine (EANM). The first Congress of the newly formed association took place in Milan in 1988. Since then the EANM Annual Congress has been held in 14 different cities with 14 different Congress Presidents (Table 1). This year the EANM is visiting Vienna for the second time in its history. This was not the result of an election at the EANM Members Assembly in a previous year, but rather because the elected President for the year 2002 (D. Maintas, Athens) could not obtain sufficient guarantees from the Greek Government that the 2002 EANM Congress would not suffer from the preparations and reconstruction being undertaken for the Olympic Games, to be held in Greece in 2004. In August 2001 the EANM Executive Committee consequently had to propose to the Members Assembly that the visit to Athens should be postponed for a couple of years and that an alternative congress site should immediately be sought for the year 2002. Based on the excellent experience with Vienna as the Congress site in 1991, the availability of the Vienna congress facility during the first week of September and the fact that the EANM Executive Bureau is now located in Vienna, it was decided to go to Vienna again. In view of these special circumstances, a decision was also made to ask the EANM President to act as the Congress President. Therefore, also on behalf of the Local Host Committee (R. Dudczak, P. Lind, H. Fritzsche,

Frans H. M. Corstens (

Department of Nuclear Medicine, University Medical Center, Geert Grooteplein Zuid 8, 6525 GA Nijmegen, The Netherlands e-mail: f.corstens@nugen.azn.nl

A. Kroiss), I most heartily welcome you to our EANM Annual Congress in Vienna.

Over the last 17 years, since its inception, the EANM has achieved a lot. Still, it is wise to reflect on what has been achieved, to realise what was attempted but not achieved, and to set ambitious aims and goals for the future.

In order to identify strengths, weaknesses, opportunities and threats, a (SWOT) analysis was made by the EANM Strategy Committee (P.J. Ell, chairman), leading to intense discussions with the Executive Board.

\section{Strengths of the EANM}

1. The EANM is the largest nuclear medicine organisation in Europe, with approximately 3,000 paying members. More than $95 \%$ of members are graduates.

2. The EANM has the biggest annual nuclear medicine congress, with more than 4,000 participants.

3. The number of scientific abstracts submitted has grown, reaching 1,500 in 2002.

4. The annual meeting has the largest industrial exhibition of close to 2,500 square meters. There is no similar event in Europe. 
5. Membership of the EANM has been open to nuclear medicine technologists for the past 3 years. Participation of nuclear medicine technologists in the EANM annual congress and in the EANM organisation is growing rapidly.

6. In the European Journal of Nuclear Medicine, the EANM has the nuclear medicine journal with the highest impact factor worldwide.

7. The task groups and committees of the EANM are active in developing guidelines and protocols for highquality nuclear medicine practice.

8. The EANM has successfully organised multicentre trials.

While a variety of aims and goals have already been achieved, there are many new opportunities for nuclear medicine in Europe and for the EANM as an organisation owing to the recent developments in both diagnostic and therapeutic medicine and the ongoing process of unification within Europe.

\section{Opportunities for nuclear medicine and for the EANM}

1. PET is the fastest growing imaging modality worldwide.

2. Nuclear medicine techniques are still significantly underused in various disciplines, e.g. medical oncology and surgical oncology.

3. Nuclear cardiology techniques are able to show perfusion, viability and function with a single investigation. No other technique can offer this.

4. The nuclear medicine diagnostic armamentarium for neurological and psychiatric disorders is developing rapidly.

5. Benefits of therapy with new radiolabelled compounds are increasingly being recognised by clinicians. Radiolabelled monoclonal antibodies have proved to offer significantly better performance in non-Hodgkin's lymphoma compared with cold antibodies.

6. In general, nuclear medicine has unique capabilities to monitor the effect of drugs.

7. Nuclear medicine can be of great help to the pharmaceutical industry in the design and development of new drugs.

8. For recently developed imaging fusion modalities, such as PET/CT, the input of nuclear medicine is crucial both for interpretation of the data and because the risks inherent to such techniques can only be handled adequately by those who are trained in and have experience with the handling of open sources of radioactivity.

9. Given the number of doctors, chemists, physicists, pharmacists and technologists who are working in nuclear medicine in Europe, the EANM has tremendous potential for further growth.
10. Within the EANM there is significant untapped expertise.

11. In many countries the overall level of nuclear medicine technologists needs to be upgraded. For the EANM it is a major challenge to make a significant contribution to this process of quality improvement.

Since the EANM is the single Europe-wide nuclear medicine organisation and because opportunities and related problems are highly similar in most European countries, it is clear that the EANM has a key role in the further development of nuclear medicine in Europe. There is no doubt that the Executive Board of the EANM is eager to play this role. Intense discussions with the Strategy Committee about their recommendations and further exchange of thoughts within the Executive Committee led to a strategic framework for the development of nuclear medicine in Europe for the next executive period. The common keyword for the renewed EANM strategy will be "professionalisation".

\section{Renewed strategy of the EANM}

\section{EANM secretariat}

Approximately 1 year ago the EANM Executive Committee installed a bureau in Vienna with professionals equipped and dedicated to the tasks they are expected to perform. No longer will a single secretary be handling the membership administration. Rather it will be dealt with by real professionals who not only know how to run an association in Europe but are also capable of acting as a professional congress organisation (PCO) for an annual congress with 5,000 participants and a budget of several million Euros; these professionals will also have the necessary experience to achieve the desired publicity for nuclear medicine. The professional secretariat will remove many administrative and organisational loads from the Executive Committee, task groups and committees, educational bodies and, last but not least, the annual Congress President.

This means that volunteers will be relieved of most administrative and organisational tasks, making it possible to better exploit what we really need from them: intellectual and strategic input.

\section{Future EANM Congress Strategy}

As already mentioned, over the past 14 years, 14 different cities have served as congress venues for the EANM. Every year the Congress President has had to "reinvent the wheel" in terms of congress organisation, handling of abstracts, etc. Each year, industry has had to address another, previously unknown PCO. Because of the lack of continuity there has been insufficient and inadequate budget control. At the same time it is a fact that, at the 
present level of membership fee, the EANM can only survive and expand its activities on the basis of the extra income obtained from annual congresses. If the EANM wants to keep the membership fee as low as it is - and the Executive Committee wants to do so in order to give every nuclear medicine professional the opportunity to become a member - then it is crucial to avoid all unnecessary costs.

The Congress in Vienna will be the first to be organised by and through our Executive Secretariat, which will thus also act as our own PCO. Based on financial data and prospects, the Congress President is confident that the financial balance of the upcoming congress in Vienna will look better compared with previous years. By introducing continuity with regard to the PCO, abstract handling, etc, it is intended to maintain tight budgetary control that will also ensure a healthy financial balance in coming years. However, for the more distant future this financial prudence implies that we shall have to carefully select congress venues with regard to features such as size, quality and costs of the congress facility, accessibility of the city and the facility, number of reasonably priced hotels in the near vicinity, etc. In this context the Executive Board recently invited all national societies to come up with proposals for congress venues that meet the requirements and criteria as formulated by the Board. We expect that the answers to the questionnaire will provide us with a list of cities and congress facilities that we can screen and eventually inspect, in order to end up with some five to ten outstanding congress facilities with good geographical spread over Europe, among which we can rotate the congress. Obviously this policy will not commence immediately, but rather after the fulfilment of commitments deriving from votes held at previous Members Assemblies. So, our Annual Congress will be held in Amsterdam in 2003, in Helsinki in 2004, in Istanbul in 2005 and most probably in Athens in 2006.

With regard to the Scientific Programme in Vienna (R. Itti, chairman), the Congress President has great expectations. The number of abstracts submitted was close to 1,500 , which is 250 more than the previous highest figure. It is also guaranteed that the exhibition will be bigger than ever, based on the space already taken by equipment producers, radiopharmaceutical companies and others.

\section{EANM educational programmes, examinations and accreditations}

Within the EANM there are at least three bodies that provide education:

- The European School of Nuclear Medicine, organising courses and seminars especially in the eastern part of Europe.

- The Nuclear Medicine Course Centre in Saclay, near Paris, now also providing courses in the English language.
- The Committee on Continuing Medical Education, providing a full educational programme at the Annual Congress.

- The EANM has even more bodies that take responsibility for setting standards for nuclear medicine education, formulating syllabi, composing examinations and evaluating the education provided by various entities:

- Union Européenne des Médecins Specialistes (UEMS), section nuclear medicine

- European Examination Boards for Nuclear Medicine

- Syllabus Committee

- Fellowship Examination Committee

The number of bodies gives rise to the question of whether there is overlap, inefficiency, lack of coordination, etc. The chairpersons of these educational bodies confirmed such thoughts and made a recommendation to the Executive Committee of the EANM that all educational and related activities should be reframed under one umbrella. For this body the Executive Committee proposes to use the name "European School of Nuclear Medicine". One other body will be responsible for examinations and accreditations.

\section{European Journal of Nuclear Medicine}

Last year the European Journal of Nuclear Medicine (EJNM, Editor-in-Chief P.J. Ell) achieved the highest impact factor of all journals in our field, not only in Europe but worldwide. Starting this year the EJNM will expand to comprise 12 regular issues per annum plus one abstract issue relating to the annual congress and one special issue dedicated to a particular topic. This year the special issue will be devoted to the thyroid, and next year to lymphoma. For 2004, it is being considered whether all guidelines and protocols produced by our task groups and committees might be combined within one special issue. The Executive Board is currently negotiating a long-term contract with the publisher, aimed at cutting expenses incurred by the EANM for the provision of our journal to all ordinary members.

\section{Task groups and committees}

At present, the EANM has three task groups (temporary) and nine committees (permanent) (Table 2). Most of these task groups and committees perform well in terms of output such as standards, guidelines, protocol and procedures. However, there is some overlap, poorly defined aims and goals and, in certain cases, a lack of clarity regarding the time frame for delivery. The Executive Board and in particular the Task Group Coordinator are currently developing a matrix for each individual task group and committee in which aims, goals, expected products, time frame etc. are specified, obviously in 
Table 2. EANM task groups and committees

\begin{tabular}{ll}
\hline Task group/committee & Chairman \\
\hline $\begin{array}{l}\text { Task groups } \\
\text { Accreditation }\end{array}$ & \\
$\begin{array}{l}\text { Quality Assurance and Standardisation } \\
\text { Dosimetry and Radiation Protection }\end{array}$ & R.A. Maisey, London, UK \\
Committees & M. Lassmann, Würzburg, Germany \\
Continuing Medical Education & \\
Cardiology & P. Lind, Klagenfurt, Austria \\
Neuroimaging & D. le Gudulec, Paris, France \\
Oncology & Vacant \\
Paediatrics & E. Bombardieri, Milan, Italy \\
Radionuclear Therapy & R. Sixt, Gothenburg, Sweden \\
Radiopharmacy & V. Lewington, Southampton, UK \\
Technologists & S. Mather, London, UK \\
EANM Strategy & W. van den Broek, Nijmegen, The Netherlands \\
\hline
\end{tabular}

close collaboration with their respective chairpersons. This process will show where there is overlap, illustrating the need for some restructuring of task groups and committees, including in relation to new developments. With such a mutually agreed matrix, the Executive Board expects better and more timely output from every task group and committee.

\section{EANM PET Institute}

Considering all the radiological sciences, and not just nuclear medicine, PET is the fastest growing imaging modality worldwide. In the United States the number of installed dedicated PET scanners grew from just over 100 in 1997 to almost 600 in 2001. A similar development is taking place in Europe.

Referring physicians are becoming more and more aware of the impact of PET on clinical decision making, management of patients and monitoring of response to drugs. At present, six indications for PET are approved in the United States (non-small cell lung cancer, colorectal cancer, lymphoma, melanoma, head and neck cancer and oesophageal cancer). Two more indications are expected to be approved soon (breast cancer and thyroid cancer) and three more are currently under review (presurgical evaluation of refractory seizure disorders, myocardial viability after an inconclusive SPET scan and evaluation of dementia).

The recent development of PET/CT provides a modality for optimal image fusion. The combination of a PET scanner with a high-end CT-scanner has clear added value:

- Accelerated attenuation correction for PET compared with correction based on radioactive sources

- Very fast X-ray CT acquisition

- Reduced total scan time

- Excellent anatomical information
- High-quality detailed image fusion

- Accurate treatment planning for radiotherapy and for (minimally invasive) surgery

The rapid expansion of PET facilities in Europe, the presence of several combined PET/CT scanners on the market, and the expected availability of PET tracers other than FDG led the Executive Board to consider the creation of an EANM PET institute, a body clearly operating within the EANM. In order to help develop such an institute, the Executive Board has installed a steering committee (E. Bombardieri, chairman) that will formulate clear aims and goals, consider possible overlap and interference with existing task groups and committees, and set time frames for the intended activities of the institute.

The aims and goals of the EANM PET Institute should include:

- Monitoring of the status of PET in Europe with regard to scanners, cyclotrons, registration of radiopharmaceuticals and reimbursement policies in various countries

- Provision of education to nuclear medicine physicians and technicians

- Development of guidelines and protocols

- Definition of evidenced-based clinical indications for PET, including monitoring of the effect of drugs

- Creation of a forum that can talk to national and international organisations with regard to legislation, reimbursement and other items

- Development and support of research programmes, including the implementation of PET in EORTC trials

- Provision of help for industry in obtaining registration for PET radiopharmaceuticals

- Design of a distribution network to guarantee that all major nuclear medicine departments in Europe will have access to fluorine-18 tracers, including good back-up in the case of breakdown of a particular cyclotron 
Table 3. EANM Annual Congress 2002, plenary lectures

\section{Lecturer}

M.N. Maisey, London, UK

G. von Schulthess, Zurich, Switzerland

H.W. Strauss, New York, USA

H. Schelbert, Los Angeles, USA

C. Halldin, Stockholm, Sweden

A. Cuocolo, Naples, Italy

T. Behr, Marburg, Germany

C. Reiners, Würzburg, Germany

M. de Jong, Rotterdam, The Netherlands
Title of lecture

Clinical PET in Europe: present status and developments

PET/CT: the best of both worlds

Imaging programmed cell death; a new opportunity for nuclear medicine

The role of nuclear medicine in the detection of pre-clinical coronary atherosclerosis

The role of nuclear medicine in the development of new drugs

The role of nuclear medicine in clinical decision making in cardiology (Marie Curie Lecture)

Radioimmunotherapy of lymphoma (Wolfgang Becker Lecture)

Thyroid carcinoma and the use of Thyrogen

Labelled peptides: current status and future developments
By the time of the Congress in Vienna, the Executive Board aims to present a definitive proposal to the Members Assembly.

\section{Technologists' activities within the EANM}

The Executive Board is particularly pleased to see that the input of technologists in the EANM is growing rapidly, not only in terms of membership but also in the provision of high-quality dedicated courses, seminars and educational material. Several other activities are currently under development. The Executive Board is playing a supporting and stimulating role, in recognition of the major growth potential for the EANM amongst nuclear medicine technologists.

\section{Relations with industry}

At the start of this year the President of the EANM and the chairman of the Strategy Committee held detailed talks with the leadership of AIPES (J. Jeans, chairman), the organisation that represents both equipment producers and radiopharmaceutical companies. The aim of the meeting was to obtain insights into the aims, goals and activities of AIPES and to investigate whether we can help each other and perhaps undertake joint activities. Over recent years there have been four significant trends within and between companies that are active in nuclear medicine. First, there have been a lot of mergers, reducing the number of AIPES members from 16 to 11 over the past 7 years. Second, companies now tend to focus on a "multi-imaging" approach, e.g. a pharmaceutical company will provide not only radioactive tracers but also $\mathrm{X}$-ray, ultrasound and MRI contrast compounds. Similar- ly, the equipment producers manufacture not only classical gamma cameras, but also X-ray, ultrasound and MRI equipment, and PET cameras. Third, most of the industry has gone global and is no longer restricted to Europe. Fourth, the investment policy is no longer driven by a particular technique. The starting point for the development of new products is the question of how to address adequately the diagnostics and therapeutics of a particular disease or group of diseases in the next 10-15 years.

It is clear that AIPES is primarily an association formed to pursue the common interests of its members, e.g. regarding the regulatory environment, transportation and reactor scheduling, and to defend those interests against external threats. We should recognise, however, that the members of this association are commercial competitors, and that collaboration is legally constrained to limited areas.

AIPES' predecessor organisation (ARPES) provided financial support for EANM initiatives such as the Empire Study, and AIPES has expressed its willingness to consider similar funding in the future if specific and mutually rewarding opportunities can be identified. Although it is unlikely that AIPES would be prepared to commit itself to the long-term financial support of our educational initiatives, it has generously offered an award of 10,000 Euros in 2002 to support a specific educational project. It is important to recognise that individual companies are welcome to support the EANM through corporate membership and individual sponsorship.

AIPES has suggested that the EANM establish a fixed number of cities where the Annual Congresses will be hosted and would prefer to deal with a single PCO, preferably within the EANM.

The AIPES leadership, together with the EANM Executive Board, will consider the formation of a "lobby- 
ing group" consisting of doctors, patients and representatives of industry in order to address supranational bodies such as the European Commission in relation to potential crises and upcoming threats to the practice of nuclear medicine in Europe.

\section{Plenary lectures at the 2002 EANM Congress}

Several major opportunities for nuclear medicine have been described above. As Congress President, I did my very best to have these topics highlighted in plenary lectures by most distinguished speakers. Table 3 provides the titles of the lectures and the names of the lecturers who will guide you into the bright future of nuclear medicine. 